\title{
Problems of the Shaping Universal and professional competencies among students of Domestic Universities in the implementation of the federal state educational standard of higher education $3++$ and ways to solve them
}

\author{
Alexandr Kiselev ${ }^{1,2, *}$, Marina Ugryumova ${ }^{1}$, Alexander Sazonov $^{1}$, and Anna Savicheva ${ }^{1}$ \\ ${ }^{1}$ Yaroslavl State Technical University, Yaroslavl, Russia \\ ${ }^{2}$ Financial University under the Government of the Russian Federation, Yaroslavl, Russia
}

\begin{abstract}
Today, Russia is actively working to introduce the Federal State Educational Standard of Higher Education 3++ (FSES HO 3++) into the educational process. At the same time, it is assumed that these higher education standards will contribute to improving the quality of training students of domestic universities for professional activities in domestic organizations. However, as practice shows, the continuous improvement of FSES HO, according to the Bachelor-Master system, does not solve the key problems associated with the training of professionals demanded by domestic organizations, who should be trained by the universities. This paper shows the problems associated with the formation of professional competencies among students of domestic universities in the implementation of FSES HO 3++, as well as possible ways to solve them and to improve the quality of training students as future professionals for domestic organizations. At the same time, all proposals are based on the practical experience of the authors and scientific analysis of existing problems, as well as feedback from employers justifying their requirements for graduates of domestic universities from the standpoint of the needs of organizations in the young professional staff they need, which allows them to successfully solve the issues of timely provision of the required level of competitiveness.
\end{abstract}

\section{Introduction}

Currently, there is a lot of talk about the need to improve the quality of higher education in Russian society. In this matter, a lot of things are being done at different levels of higher education management, but, unfortunately, more often than not solving the problems of higher education, but giving rise to more and more new problems. This is evidenced by the constant "improvement" of FSES HO, as one representative of the Ministry of Science and Higher Education said at a meeting with representatives of the universities while introducing FSES HO 2, which is being conducted at the State University of Management. And nowadays, educators of domestic universities have the impression that they are simply forced to deal with the processing of a huge amount of educational documentation, which 
not only does not improve the quality of education, but reduces it due to the "separation" of educators from the educational process to work with documents. At the same time, seeing the formal nature of improving FSES HO and the lack of time for such work, university staff, for the most part, also formally refer to the development and processing of educational documentation for the "improved" FSES HO. And today, the time has come not only to discuss these issues and problems, but, taking into account our rich experience in organizing higher education as vocational education, scientific developments in this area, to solve them from the standpoint of the demand of domestic organizations in the professionals they need and the interests of students who have chosen for themselves entering a university, a certain area of their future activities. The paper outlines the key problems of the formation of such professional competencies in university graduates that will allow them to successfully work in their chosen specialty in domestic organizations and to meet the need for young professionals in the organizations they need.

\section{Research methods}

In order to study the identified problems and to determine the directions for improving the organization of the formation of the necessary professional competencies in university graduates, which make the graduate attractive for the organization as a professional, we have used the method of participatory observation, analysis of FSES HO "improvement" over the past 10 years, surveys of the teaching staff and university students, studying the reviews of university graduates and representatives of organizations, scientific publications of researchers on the indicated problems, as well as processing information from a questionnaire survey of graduate students of Yaroslavl State Technical University about their assessment of preparedness in the organization in their chosen specialty. Research materials on this topic were repeatedly submitted for discussion at various scientific and practical conferences.

\section{3 research results and their discussion}

There is no doubt that the development of society in modern conditions makes its own adjustments to the organization of training for future specialists in universities for various subjects of the Russian economy. Today, this is reflected in the FSES 3++ being introduced in Russian universities, which defines the requirements for the formation of universal and professional competencies in students [1].

This is the development of a competency-based approach to teaching students. However, the implementation of several generations of FSES HO from the standpoint of the competence-based approach today, as practice shows, does not give the desired result.

The first problem is related to the fact that the analysis of works on the problem of the competence-based approach allows us to conclude that there is currently no unambiguous and scientifically grounded understanding of the concept of "competence". At the same time, there is a wide range of opinions on the formulation of the concept of "competence", despite the fact that researchers use both European approaches to their understanding and domestic ones. Moreover, the concept of "competence" is often confused with the concept of "awareness". Let us emphasize that the linguistic aspect of this problem turns out to be important. So, M.E. Bershadsky in the Pedagogical Discussion Club "Competence and Awareness: How Many of Them Does a Russian Schoolchild Have" (Auditorium.ru portal, 2002) considers the penetration of the concepts "competence" and "awareness" into the Russian language as another manifestation of the process, as a result of which "educators 
will soon begin to write texts by writing down English words using the Cyrillic alphabet" [2].

According to A.G. Bermus, who studied these issues, competence is a systemic unity that integrates personal, subject, and instrumental features and components, that is, competence is considered to be as the goal of education [3]. At the same time, domestic researchers V.A. Rukavishnikov and V.V. Halueva believe that "competencies should be the tasks of the formation of competence. These concepts can pass one into another as a goal and objectives in a complex activity, if, for example, we consider separately simple types of activities included in a complex activity" [4]. But if competencies are understood as purpose and objectives, then the question arises of what then needs to be formed in students at the university, when in FSES HO $3++$, it is about the formation of professional or universal competencies?

A. V. Khutorskoy considers as a competence an already alienated, predetermined social requirement (norm) for the educational training of a student, which is necessary for his/her effective productive activity in a certain area [5]. But again, there is no specifics in what this requirement (norm) is. As a result, A. V Khutorskoy further writes that "in contrast to the Western (European) understanding of competencies that are ordered by the employer [6], we proposed the term "educational competence", which characterizes the mutual order for education - both from an external society and from the side of the student himself/herself" [6]. Thus, he concludes that competence is a social requirement (external norm) for the educational preparation of a student, which is necessary for his/her highquality productive activity in a particular area. And competence is the possession, the possession of the corresponding competence by the student (the internal quality of the student).

At the same time, N. L. Goncharova defines competence as "a complex structure, consisting of various elements as some property of a university graduate" [7]. But we need to decide what property of the graduate she is talking about.

For example, G. K. Selevko understands the subject's readiness to effectively organize internal and external resources for setting and achieving a goal by competence [9]. And again, it is not clear what needs to be formed in students in this case.

But I. A. Zimina generally writes the following, "For me, competencies are notwithstanding (and here I am following J. Raven), notwithstanding what area they belong to, these are factors that contribute to the achievement of the best result in activities, in learning, in whatever. It can be a motivation, it can be an ability, it can be an emotion, it can be knowledge, skills - this is all that leads to the result and awareness of oneself as a subject of this activity" [10].

We believe that even such a brief overview of identifying the essence of competence shows that university staff does not understand the essence of competencies and simply "pull up" academic subjects that formally allow the formation of some professional and universal competencies inherent in FSES HO 3++. At the same time, for example, even universal competencies, that is, competencies that are the same for all areas of training, even in the same university in different areas, are planned to be formed by different subjects, that is, in this case, the tasks of not students in ensuring their professional readiness are solved, but the issues of lecturers to provide yourself with a teaching load. In doing so, most often, competencies in FSES HO 3++ mean certain abilities or readiness of trainees for something, for example, for making managerial decisions. Meanwhile, a student's readiness for something does not mean readiness for some kind of activity [11].

From the point of view of psychology and pedagogy, the personality characteristics of a person should be considered to be as ability. So, for example, if a person does not have the ability to learn to play musical instruments, since he/she has no ear for music, then it will be impossible to make a professional musician out of him/her, no matter what teaching 
methods are used. And the readiness of a person is his/her psychological state, not professional training. Or a person really wants to drive a car, so he/she is ready for this in his/her psychological state. But if he/she is not trained in this, then a good result in driving can hardly be expected from him/her. In the children's book S.Ya. Marshak was written, "I would go to the pilots, let them teach me". And a professional worker is not always ready to do his job well: if, for example, he is sick, that is, he has knowledge and skills, but physically he cannot apply them in practical work [12]. Consequently, the concept of competence should be "linked", not with the concepts of abilities and readiness, but with the preparedness of a university graduate for a specific professional activity.

Thus, studying the problem of the concept of "competence", we have concluded that it is necessary to consider to be as a competence a set of knowledge and skills of a student to perform certain work operations in the chosen direction of training, which, in the complex, should fully correspond to the future work of a graduate in organizations, according to the chosen for training in the field of study [11]. As a result of this approach, it can be assumed that the totality of such competencies should represent the essence of the activity of the university graduate, for which he/she is preparing at the university. Consequently, the readiness and ability of the student are needed at the input of his/her training as initial parameters for training, and competencies - in the end, determining the formation of the graduate for practical work in his/her chosen specialty, that is, his/her readiness for practical work. Let us take a simple example. Thus, when training a seller, it is necessary to form his/her professional competencies. To do this, his/her future professional activity should be "categorized" into a number of different possible operations, the knowledge and experience of which can be designated as competencies. First, he/she needs to be taught how to turn on the cash register and give him/her practical skills. Then he/she needs to be given the knowledge and skills on how to make out a buyer's receipt. A situation may arise that the buyer refuses to purchase. The seller should know how to act in this situation and be able to arrange and to work everything out. A situation is possible when the tape runs out in the cash register or the program hangs up. And for such specific situations, the trainee should acquire knowledge and skills so that, as a whole, he/she can do his/her job in the organization. This is precisely the essence of competence-based learning as practiceoriented learning. Consequently, in FSES HO, the main professional competencies should be clearly formulated, comprehensively and fully revealing the practical component of the future professional activity of the graduate. In this case, it is possible to build a structural and logical structure of training a university graduate for future professional activity in the chosen field of study.

The second problem is related to the fact that the developers of FSES HO cannot clearly determine how to distinguish professional and universal competencies as components of the professional activity of a university graduate. As a result, occupational standards differ significantly from educational standards today. In other words, universities teach students not what graduates need in their professional activities, but "form" their "vague" abilities to analyze something or readiness for communication in a team, etc. And each university, under one field of study, defines many different profiles that are not focused on a specific specialty, but should be "beautiful" in terms of their formulation and attractiveness for applicants who do not yet understand what they will need in practice, or who are aimed at "getting a diploma", and not any particular specialty. In addition, FSES HO 3++ already has a list of occupational standards recommended for use in the university attached to them, from which it is recommended to choose several competencies for the formation of students at the discretion of the university. But if we think about it, it turns out, for example, that we should teach a future pilot anything, "forming" his readiness, that is, the desire to fly, and the ability to take responsibility for the flight, but we will choose only one competence from the professional standard- to learn take off. It is clear that such a university graduate 
should not be allowed to fly, since he is not prepared for them and cannot professionally manage them.

And today the educational community already understands that the fourth generation of FSES HO will probably be required, in which this problem will be solved. For example, V.A. Rukavishnikov and V.V. Halueva note that "the goal of the fourth generation FSES $\mathrm{HO}$ is to improve the requirements for the educational process by taking into account the content of occupational standards, which determine the characteristics of the qualifications necessary for an employee to carry out a certain type of professional activity" [13]. This problem is still far from being solved. But we can lose the domestic engineering corpus, having received it is not clear what Bachelors: mechanical engineering, economics, etc.

The third problem, as we see it, is related to the fact that universal competencies should be linked to professional competencies that allow a graduate of a university of any direction of training to successfully work in teams of organizations, to make a managerial career, and to organize the work of the organization's employees in order to perform production (professional) tasks. That is why they are universal ones, which should be the same in all universities and at all faculties (institutes) of universities, since they determine the preparedness of university graduates to work successfully in teams. However, today in the implementation of such competencies, the formation of which is determined by the lecturers themselves, they see the loss of "their hours" of work. As a result, they "transfer" the formation of universal competencies in the curricula to the subjects of the department, which, in principle, cannot solve this problem. At the same time, this approach to the formation of universal competencies does not make it possible to transfer in the first years not only to another university of the same profile, for example, with a move to a new place of residence, but even from faculty to faculty. You know, in the Address to the Federal Assembly in January 2020, the President of the Russian Federation V.V. Putin has proposed to allow students to change their specialty after their second year. Currently, students cannot do this, since training programs even in universities with the same profile differ greatly [14]. All of this will require a new redesign of FSES HO as the fourth generation of FSES HO. But university lecturers spend a lot of effort on reworking educational documentation, seeing and understanding that this is formal work that will not have a serious impact on improving the quality of student learning, but will "detach" lecturers from direct educational work with students.

The fourth problem is related to the fact that in order to ensure the practical orientation of training, FSES HO 3++ recommends having active specialists of organizations at the departments of universities in the positions of the teaching staff. The idea is good. But in practice, it is poorly realizable. After all, we need to attract a specialist from the organization who is busy in production and cannot devote time to spend with students as a professional lecturer. And it often happens that the attraction of such specialists from organizations to participate in the educational process takes place formally, "just to put in an appearance", in order to fulfill the requirements of FSES HO $3++$, and their teaching load is "shirked off" to the existing lecturers of universities, but not paid to them. All this causes a certain pressure in the teaching staff. But at the same time, the lecturer's extensive experience in real production in organizations in certain positions that have switched to teaching on an ongoing basis, for some reason is not considered as such: in accordance with FSES HO 3++, an active specialist of the organization is needed [15].

All this allows us to draw certain conclusions on the problem under study.

\section{Conclusions}

Today, the analysis of the issues outlined in the paper allows us to say that from the standpoint of the competence-based approach, the formation of universal and professional 
competencies among university students is not aimed at training professionals, in-demand professionals, although the majority of organizations are interested in young and creative specialists who can provide them with the required level of competitiveness.

And today's graduates of domestic universities for the most part are not in demand by organizations in terms of their preparedness as professionals. And the State, allocating huge money to ensure the work of universities, loses in the person of unclaimed university graduates a huge potential for its development.

At the same time, it is no secret that many universities, primarily regional ones, have an outdated material and technical base, since there is no funding for its improvement in the required volume. In doing so, the issues of passing industrial practice by graduate students are often resolved through the lecturer's personal contact with any organization. The Soviet system of passing industrial internship by students of domestic universities was destroyed and the new one was never created.

Certainly, universities are trying to somehow meet the requirements of the time for their development, looking for sponsors from among regional organizations for their development and improving their material and technical base. However, fundamentally new FSES HO are needed today, since no current "improvement" of FSES HO can improve the quality of professional training of a future specialist. And teaching a university student as a professional without a modern educational and material base is like teaching a person to swim without a pool or a water reservoir. He/she will know the theory of how to swim, he/she will be able to master swimming, and he/she is ready to master it, but he/she will never swim, since he/she himself/herself did not try to do it during his/her training. Thus, the time has come to address these from the standpoint of the State interests and the interests of the domestic economy. Otherwise, over time, there will be no specialists in Russia who can successfully work in organizations. And this problem needs to be addressed urgently, since we are already lagging behind the developed countries of Europe and China in the issue of training professionals for high-tech production.

This necessitates the modernization of the organization of the activities of universities in the implementation of such FSES HO, which will really be aimed at training modern professionals that are needed by domestic organizations and are able to provide them with the required level of competitiveness. And nowadays, it is no longer necessary to deal with the implementation of FSES HO 3++ in universities, but the preparation of new FSES HO, which will be aimed at training those professional specialists in universities that are in demand by domestic organizations. And the organization of teaching students in such conditions should not become a problem for university staff, a work "into the void". Probably, today is the time when the necessary material and technical base should be created in universities, including the provision of lecturers and students with the equipment they need, the necessary methodological support for teaching students, and the systematic and planned preparation of lecturers and students to work in real organizations in real conditions. And domestic organizations themselves will be interested in developing the educational and material base and improving the formation of universal and professional competencies among students in universities, if they see in university graduates the potential for their development and ensuring the required level of competitiveness.

\section{References}

1. Portal of Federal State Educational Standards for Higher Education, http://fgosvo.ru/

2. V. A. Dubrovin, Problems and Prospects for the Implementation of the CompetenceBased Approach in Education

3. A. G. Bermus, Eidos Online Journal (2005) 
4. V.A. Rukavishnikov, V.V. Halueva, FSES HO is Three plus or Is It Two with a Minus?, http://dgng.pstu.ru/

5. A. V. Khutorskoy, Educational Competencies and Methodology of Didactics, https://www.khutorskoy.ru/

6. Council of Europe: Symposium on Key Competencies for Europe (1996)

7. A. V. Khutorskoy, Eidos Online Journal, (2002) http://www.eidos.ru/

8. N. L. Goncharova, ParadigmCollection of Scientific Works of NSFU, 5 (2007)

9. G. K. Selevko, Rural School: Russian Pedagogical Journal, 3, 29 (2004)

10. I. A. Zimnyaya, Problems of the Quality of Education (2003)

11. A. A. Kiselev, Pedagogy, Psychology, 8 (2020)

12. A. A. Kiselev, Trends in the Development of Education: Educator, Educational Organization, Society, 64 (2020)

13. V.A. Rukavishnikov, V.V. Halueva, FSES HO is Three plus or Is It Two with a Minus? http://dgng.pstu.ru/

14. In 2021, University Students Will Be Able to Change Their Specialty After the 2nd Year, https://hdroliki.ru/

15. A. Kiselev, M. Ugryumova, A. Sazonov and A. Savicheva, SHS Web of Conferences, 93 (2021) 